successful efforts in this direction that have resulted from that realisation. It fell to Capt. Brooke-Smith to explain to a committee of the Chamber of Shipping of the United Kingdom in 1921 some of the advantages which might accrue to navigation from the more general use of reliable thermometers as well as reliable barometers, and the report of that committee to the Chamber of Shipping included recommendations in respect to both these items. Apart from their value in forecasting, reliable measurements of atmospheric pressure at sea should eventually become important for pilots of aircraft when far from land, who will rely on them for obtaining correct indications of height from their altimeters, and for that purpose will have to obtain them by wireless from ships.

AN equal improvement in thermometers, Capt. Brooke-Smith states, has not yet taken place. $\mathrm{He}$ points out, however, that the information about temperature required at sea can generally be obtained from the broadcasts made on 2100 metres wave-length by British $A$ class selected ships, which broadcasts have a range of 1,500 miles; such ships are to be found on all main trade routes, and all are equipped with thermometers certified by the National Physical Laboratory and exposed in Meteorological Office screens. The thermometers on such ships, when the ship is in port, afford a means whereby, through the courtesy of the captain, other ships may test their own thermometers and ascertain their accuracy. In answer to the frequently made suggestion that more British merchant ships should be equipped with instruments provided through the Meteorological Office, Capt. Brooke-Smith points out that the existing meteorological personnel at the ports is not adequate for dealing with such an increase, which would also throw excessive extra work on the divisions of the Meteorological Office concerned with maintaining the marine meteorological equipment, that is, the marine and instrument divisions.

\section{Sixteenth Century Central Europeans in England}

Is the Matice Moravská (Brno, Czechoslovakia), Prof. O. Odložilik has just published the results of extensive researches among documents and manuscripts from British libraries and those in Holland and central Europe, under the title "Visits from Bohemia and Moravia to England, 1563-1620". He shows how scholars in Britain and the remoter parts of the Continent managed to keep in touch with each other's discoveries, views and writings. This contact was as strong between men of science (astronomers, mathematicians and others) as it was between theologians or historians. The period under review preceded the influx of refugees from the Thirty Years' War, but the question whether Komenský (Comenius) visited England in 1613 (that is, when he was only twenty-one years of age) is again raised. Whilst it is extremely unlikely that the great educationist did come to England prior to 1641 , it is clear that many Bohemian and Moravian students and savants (including Peter Vok and Thaddeus Hajek) visited
Oxford and Cambridge, and made contact with such sixteenth century Englishmen as Dr. John Dee, Francis Bacon, Sir Philip Sidney, Lord Burghley and the Earl of Essex. Some, like Charles of Zerotin, acted as diplomats between Bohemian monarchs and the British Crown at this period when culture and science began to flourish again after the Dark Ages.

\section{Flashes of Lightning}

According to a message from Science Service, flashes of lightning photographed by a cine-camera by J. W. Beams, L. B. Snoddy and E. J. Workman, of the Universities of New Mexico and Virginia, were shown at the recent meeting of the American Physical Society. The progress of the flash was shown to be similar to that of a nail gradually piercing a wooden board step by step under the successive blows of a hammer. Their cameras showed that the first flash extended halfway from the cloud to the earth. A second one followed the path of the first but went six tenths of the way, while a third travelled seven tenths of the distance. The fourth flash reached all the way and struck the earth. Four other flashes from the cloud to the earth followed at short intervals of approximately one hundredth of a second.

\section{Institution of Gas Engineers}

AT the seventy-third annual general meeting of the Institution of Gas Engineers which opened in London on May 26 the following medals were presented : Institution Gold Medal, to George Dixon, for a paper on "Problems and Answers in the Reconstruction of Manufacturing and Distribution Plant, Nottingham"; H. E. Jones London Medal, to W. L. Boon, for a paper on "The Preparation, Marketing and Utilization of Coke"; Institution Silver Medal, to T. P. Ridley, for a paper on "Gas Tariffs"; Institution Bronze Medal, to William Hodkinson, for a paper on "Benzole Recovery and the Production of Motor Benzole". Mr. Stephen Lacey, controller of gas sales, Gas Light and Coke Company, London, was elected president of the Institution for the year 1936-37, and Mr. H. C. Smith, chief engineer, Tottenham and District Gas Company, and Mr. Robert Robertson, engineer and works manager, Bristol Gas Company, were elected vice-presidents.

\section{South African Association for the Advancement of Science}

UNDER the presidency of His Excellency the Right Hon. the Earl of Clarendon, Governor General of the Union of South Africa, the South African Association for the Advancement of Science will hold its thirtyfourth annual session on October 5-10 in Johannes. burg. It is noteworthy that the meeting coincides with the celebrations connected with the jubilee (fifty years) of Johannesburg, and with the holding there of the Empire Exhibition. Sectional presidents are: A, Dr. E. J. Hamlin, city engineer, Johannes. burg ("The Researches of a City Engineer's Department"); B, Prof. E. D. Mountain, professor of geology and mineralogy at Rhodes University College, 